\title{
Proximal spinal muscular atrophy
}

\author{
MAURICE GROSS
}

From the Department of Neurology, St. Thomas's Hospital, London

It has been known for some time that cases of muscular atrophy can occur in young people which clinically resemble limb girdle muscular dystrophy but which electromyographically and histologically can be shown to be due to damage to the spinal motor neurone. Investigation of the family frequently reveals further cases, and the course and prognosis is often benign and relatively non-progressive and similar in many ways to the course of limb-girdle muscular dystrophy. Similar cases occurring in a slightly older age group are likely to be confused with motor neurone disease, and thus given an unnecessarily poor prognosis. It is not until they are seen to survive much longer than would be expected and their disorder remain confined to the lower motor neurone, that it becomes evident that one may be dealing with a different condition. Three cases are recorded here which have many similarities clinically, electromyographically, and histologically; the first two started in late adolescence and were initially thought to have the clinical features of muscular dystrophy, and the third case started in middle age and was for many years thought to be motor neurone disease.

\section{REPORT OF CASES}

CASE 1 A 15-year-old apprentice printer was admitted to St. Thomas's Hospital in 1960 for investigation of difficulty in rising from the lying position for the previous three years. He had always been well and was the only child of healthy parents; no known relatives had any muscular or locomotor disorder, nor was there any known consanguinity. At the age of 12 years he began to notice difficulty in running when his legs would give out after short distances. This slowly got worse, but he was able to play football until he was 14. At this age he fell over one day and had difficulty in getting up, and this disability had persisted ever since; he had to get up by rolling over on to his abdomen and pushing himself up with his hands. He had not noticed any weakness in his upper limbs, but for the previous few months he had experienced occasional cramps in his hands and feet.

Examination revealed an overweight boy with proximal weakness of all the muscles round the shoulder and pelvic girdles, most marked in the hip flexors, glutei,

'Present address: The National Hospital, Queen Square, London, W.C.1. and quadriceps. There was no obvious wasting, no fasciculation, and sensation was normal. Biceps and supinator reflexes were just obtainable but triceps jerks were absent. In the lower limbs knee jerks were unobtainable but ankle jerks were present; plantar responses were flexor. No abnormality was found on general examination.

Special investigations Electromyographic studies showed reduced motor unit activity in the affected muscles, and what activity there was comprised large potentials of the type encountered in myelopathy (Fig. 1a).

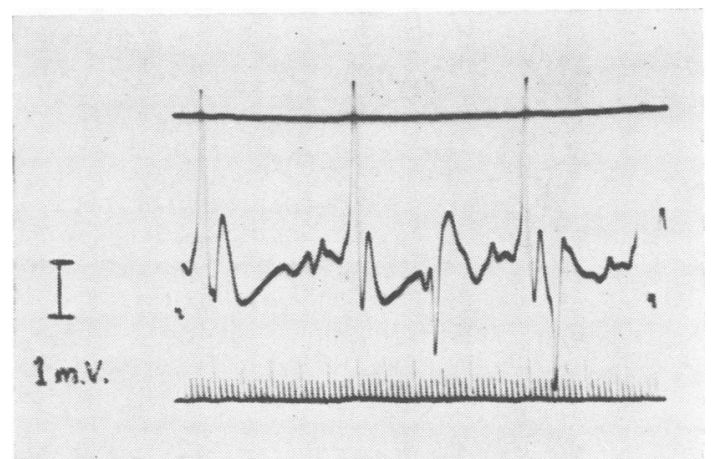

FIG. 1a. Electromyographic tracing from the lt. extensor digitorum communis in case 1, showing large amplitude potentials.

Muscle biopsy from the left deltoid (Dr. V. MacDermot) showed marked variation in muscle fibre calibre, both hypertrophic and atrophic fibres being seen. There was a considerable increase in perimysial fibrous and fatty tissue, and several intramuscular nerve bundles showed loss of myelinated fibres. Methyleneblue-stained sections showed complex distal nerve fibre branching and frequently the innervation of a number of muscle fibres by branches of a single nerve. The motor end-plates varied in size and were often large and complex. The appearances were considered to be those of longstanding neurogenic muscular atrophy (Fig. 2a).

Cerebrospinal fluid showed a normal protein content and negative Wassermann and Lange reactions. Subsequently he has been followed up as an out-patient and has become but little weaker. For four months in 1961 he was given oral prednisone, initially $30 \mathrm{mg}$, later 


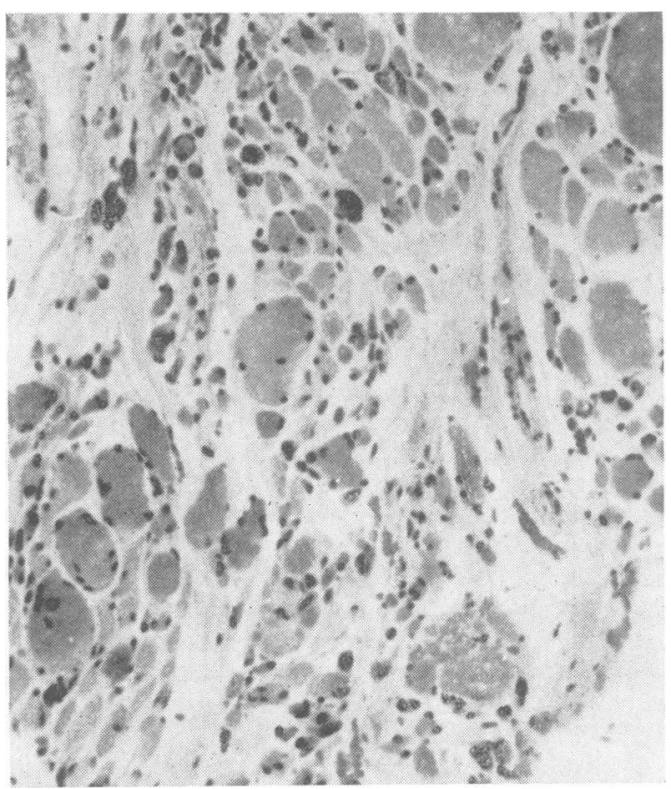

FIG. 2a. Lt. deltoid muscle biopsy section from case 1, showing variation in calibre of groups of muscle fibres consistent with longstanding neurogenic atrophy.

reduced to $20 \mathrm{mg}$. daily, which did not appear materially to benefit him or alter the course of the disease. When last seen in December 1964 he was working in a clerical job, although for the last few months he was no longer able to walk to his office a mile away. His main disability was still in rising from the recumbent or sitting position due to a weakness of the flexors and extensors of the hips. There was at this time moderate weakness of proximal limb muscles with some wasting, and depression of all reflexes except the ankle jerks. Estimations were made of the serum enzymes: creatine phosphokinase was 3.3 units (normal 0.2 to 1.5 units) and aldolase 15.4 units (normal 3 to 10 units). The creatine level was $0.60 \mathrm{mg} \%$.

Electromyography has been repeated yearly since he was first seen and remains unchanged. At the last examination in July 1965 , nerve conduction studies were made along the right ulnar nerve, and the responses showed normal latencies and durations. The nerve conduction velocity over the elbow-to-wrist and axilla-to-elbow segments of the nerve was $40 \mathrm{~m}$./second which is within the normal range.

CASE 2 A 22-year-old unmarried dental technician was admitted to St. Thomas's Hospital in September 1964 for investigation of muscular weakness for the previous five years. Six years before admission he had had an illness diagnosed as glandular fever, but had otherwise always been healthy and athletic. He was one of three siblings, an older brother and sister being healthy and without any muscle disorders; there was no known history of consanguinity or muscular weakness in the family.
At the age of 17 years he began to notice some difficulty in climbing stairs because of weakness in his thighs. His legs had always been thin and he did not think that they had become thinner nor had he experienced any muscular cramps. His arms had always been thin, but he had noticed no weakness in them. He claimed that his disability at the time of admission was no greater than it had been at the time of onset of the condition five years previously.

On examination he was a thin, bearded man of normal intelligence. There was gross wasting and moderate weakness of the muscles around the shoulder girdle and the proximal arm muscles, but the distal musculature retained almost normal bulk and power. There was no detectable trunk weakness, but in the lower limbs there was considerable wasting of quadriceps and glutei with commensurate weakness. Bursts of fasciculation were seen in shoulder and thigh muscles. Sensation was normal, all tendon reflexes were obtainable only with difficulty, and the abdominal reflexes were absent. Plantar responses were flexor. General medical examination was normal.

Special investigations Electromyographic studies of the affected muscles revealed definite fibrillation at rest; in addition fasciculation potentials were recorded and occasional high frequency discharges. The volitional motor unit pattern was reduced and some of the potentials were of longer duration than normal and polyphasic Nerve conduction studies in the ulnar nerve were norma 5 , 6 The appearances were those of a myelopathy (Fig. 1b

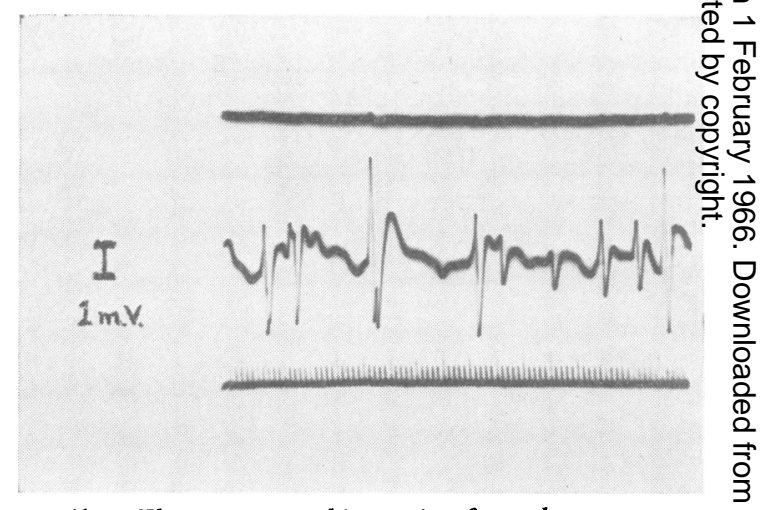

FIG. 1b. Electromyographic tracing from the rt. extensor digitorum communis in case 2, showing large potentials of more than $5 \mathrm{mV}$. amplitude.

A muscle biopsy showed groups of small muscle fibres which had lost their striation and showed granulation and sarcolemmal proliferation. The appearances suggested neurogenic atrophy (Fig. 2b).

The cerebrospinal fluid was of normal composition and the Wassermann and Lange reactions were negative.

The serum creatine level was $1.3 \mathrm{mg} . \%$ (normal less than $0.6 \mathrm{mg} . \%$ ), creatine phosphokinase 3.0 units (normal 0.2 to 1.5 units), and aldolase 20.8 units (normal 3 to 10 units).

Subsequently the patient has been followed-up in the Out-patient Department, and when last seen in May 1965 


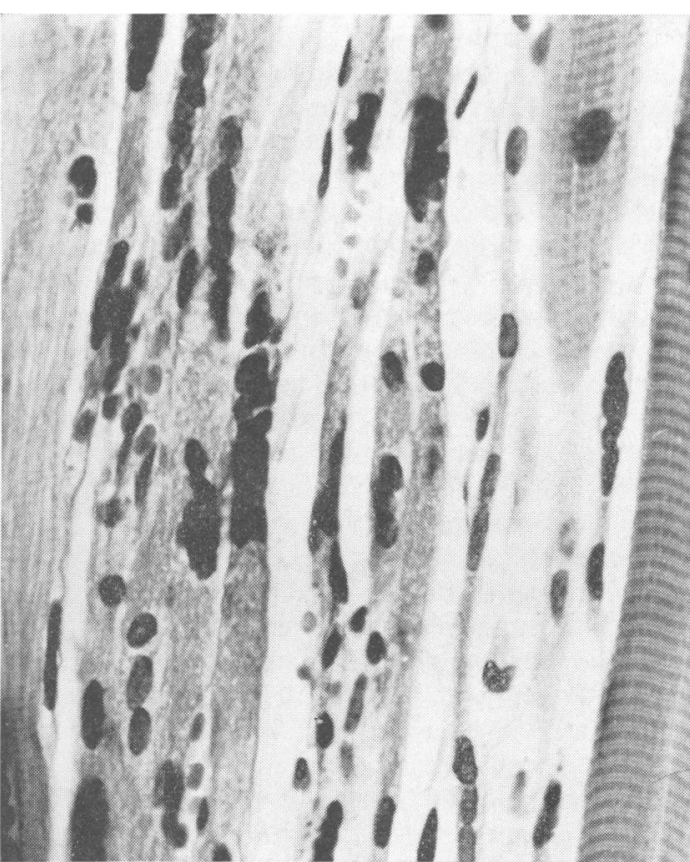

FIG. 2b. Muscle biopsy from case 2 showing variation in size of muscle fibres in longitudinal section; the smaller fibres have no striations and show granular degeneration.

remained unchanged. He was able to walk for two or three miles on the level and climb 50 stairs slowly, but found difficulty in getting up from a chair without using his hands because of weakness of the hip muscles.

CASE 3 A 49-year-old motor tester was first seen at St. Thomas's Hospital in November 1953 by the late Dr. J. St. C. Elkington. The first symptoms of muscular weakness had started 11 years previously when at the age of 38 years he had been discharged from the Home Guard because his legs were not strong enough for him to keep up with the other men during training marches. This weakness remained very slight for several years. At the age of 46 he had to give up playing the violin because his right wrist had become too weak for bow movements. He had noticed that his hands had become thinner and that his muscles were twitching frequently. His voice tended to fatigue easily and on one occasion he had had slight difficulty in swallowing for a short time. Previously he had had no significant illnesses and he was the only child of healthy and unrelated parents who were not affected by any muscular wasting or weakness; there was no known history of any familial muscular disorder.

On examination he was seen to be thin with mild bilateral wasting and fasciculation in the facial muscles, and his speech was nasal, defective in the production of labial sounds, and easily fatigued. His tongue was small and symmetrically wasted, and there was wasting of the neck, shoulder-girdle, arm and leg muscles, mainly proximally, with hypotonia and fasciculation. Tendon reflexes were reduced in the right arm and both legs, and plantar responses were unobtainable. There was no sensory disturbance. He was diagnosed as having an unusual type of motor neurone disease. Electromyography at that time revealed fibrillation in both upper and lower limb muscles and large amplitude potentials on minimal volition (Fig. 1c). Intravenous injection of $10 \mathrm{mg}$. edrophonium chloride increased the fasciculation and provoked it in other parts of the body where it had not until then occurred.

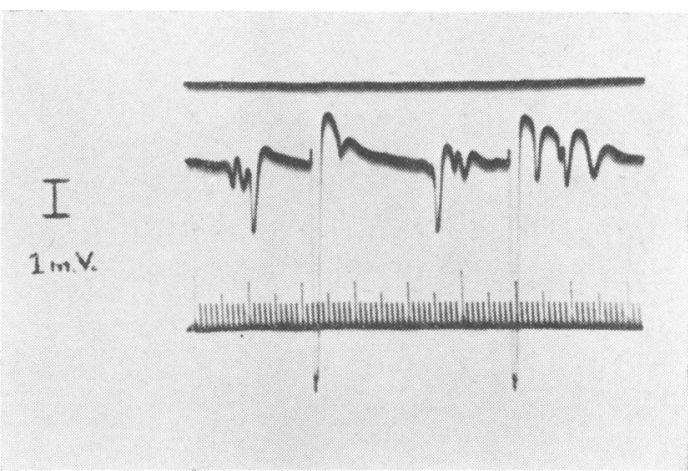

FIG. 1c. Electromyographic tracing from extensor digitorum communis in case 3, showing extremely high amplitude potentials.

Thereafter electromyography has continued to show the same changes twice yearly. In 1957 he was admitted for examination of the spinal fluid which was found to be normal in all respects; the protein content was $25 \mathrm{mg} . \%$ and the Wassermann and Lange reactions were negative. Over the next four years he was seen regularly as an outpatient and there appeared to be only a very slight increase in weakness. In 1958 he was again admitted for muscle biopsy by Dr. Violet MacDermot. The biopsy was reported on as follows:

Muscle biopsy (lt. peroneus longus) The general picture was of well-marked focal atrophy of muscle fibres. The atrophic fibres were markedly reduced in calibre. A considerable number of fibres were, however, of normal calibre; among these were scattered fibres showing basophilic staining, central emigration of nuclei, and degenerative changes in the cytoplasm. Nerve bundles showed considerable loss of myelinated fibres. Methyleneblue-stained sections showed variation in calibre of intramuscular nerve fibres and nerve bundles appeared poorly innervated. Motor end-plates were degenerate and some terminal branching was seen. The picture was that of a focal neurogenic muscle atrophy with unusual degenerative changes occurring in the muscle (Fig. 2c).

Also at that time the serum creatine level was 0.99 mg. $\%$ (normal less than $0.6 \mathrm{mg} . \%$ ) and serum creatine phosphokinase 2.79 units (normal 0.2 to 1.5 units).

Since that time his condition has hardly deteriorated. He was last seen in August 1965, some 23 years after his initial symptoms, not greatly incapacitated, able to walk 


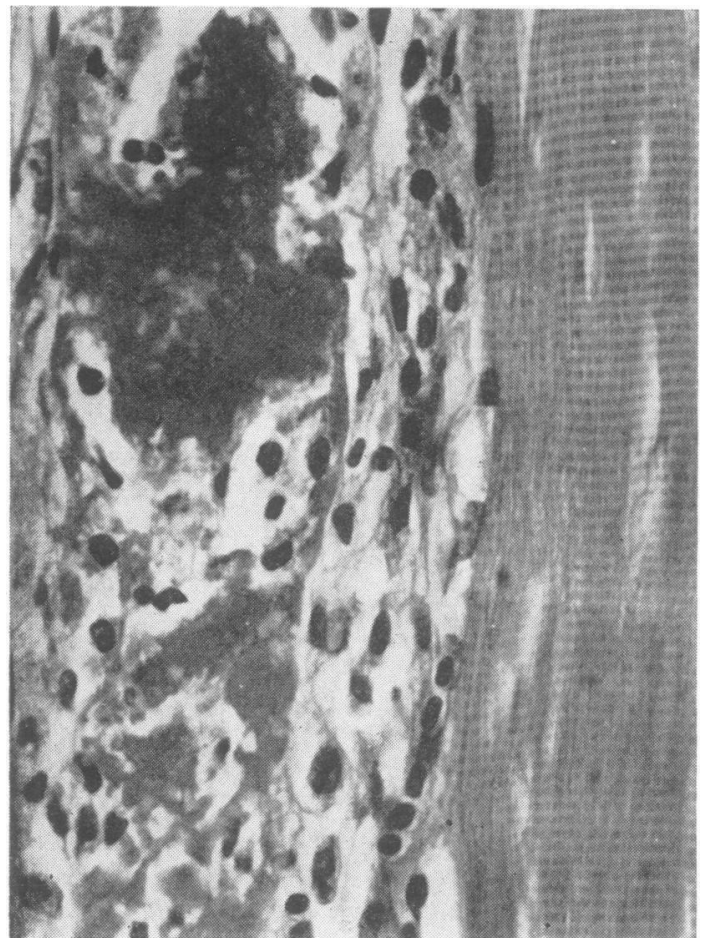

FIG. 2c. Part of section of muscle biopsy (left peroneus longus) from case 3, under high power ( $\times$ 500), showing area of floccular degeneration of muscle.

and to enjoy his retirement. Examination showed that his muscles had wasted a little more, both proximally and distally, fasciculation was prominent and widespread and included the tongue, and the tendon reflexes were unobtainable. There were no upper motor neurone signs and sensory examination was entirely normal.

\section{REVIEW OF THE LITERATURE}

It is relevant at this point to discuss the previous literature describing muscular atrophy of spinal origin not only in the age groups covered by the three cases presented above, but also as it occurs in infancy and childhood. Just before the turn of the century Werdnig (1891 and 1894) and Hoffmann (1893 and 1897) in four articles described several cases of a rapidly progressive, familial muscular wasting and weakness occurring in infancy. These cases were summarized by Hoffmann in 1897; most of them had died in the first year of life, although Werdnig's cases showed some variation in severity, one child surviving to over 6 years of age. The pathological basis for the disease was found to be spinal atrophy.

In 1950 Brandt reviewed over 100 cases of infantile muscular atrophy. The majority had started their $\bar{Z}$ disease in the first year of life and died before the age of 4 years, but several survived until lateo adolescence. Of those who were still living, the two oldest were aged 18 and 20 years but were completely disabled by extreme weakness and wasting.

Wohlfart, Fex, and Eliasson described three families in 1955, containing seven cases of a relatively non-progressive proximal muscular atrophy with an onset in childhood or adolescence. Most of these cases were already in their teens or twenties when $\stackrel{5}{\rightarrow}$ described. Four cases were studied electromyo- 0 graphically, which indicated a spinal origin to the wasting, and there was further confirmation of the $\frac{\bar{c}}{\frac{5}{5}}$ neurogenic nature of the disorder from muscle $\stackrel{\mathbb{Q}}{\stackrel{\mathbb{Q}}{2}}$ biopsy in one of these cases.

A year later in 1956, Kugelberg and Welander described 12 patients with an hereditary type of juve- $?$ nile muscular atrophy all of whom had been con- $\overrightarrow{\vec{\omega}}$ sidered initially to have muscular dystrophy. The $\omega$ disease started at ages which varied between early childhood and adolescence, and progressed onlyo very slowly over the course of many years. Most of 0 the cases belonged to families in which another one or $\overrightarrow{-}$ more members could be found with a similar disorde $\bar{w}, 0$ and there appeared to be a recessive inheritange응 without sex linkage. The lower limbs were usualof affected first, mainly proximally, and the upperr limbs were not affected for many years. The weak-을 ness was accompanied by wasting of muscle, particolarly around the limb girdles, and fasciculation was often seen or could be provoked by neostigmine $\overrightarrow{0}$ Tendon reflexes gradually disappeared, although the ankle jerks were frequently retained until late in the disease. Plantar responses were normal, and theo cranial innervated muscles remained intact. Electromyography showed characteristic changes of lower motor neurone damage and muscle biopsy showed $\frac{\mathscr{}}{\varnothing}$ neurogenic atrophy.

In 1961 Byers and Banker reviewed 52 cases of $\overrightarrow{\overrightarrow{0}}$ infantile muscular atrophy and lay stress on the 3 . variability in clinical and pathological severity. In general they found that the earlier the age of onset, the more severe and rapidly progressive the disease was likely to be; the least severely affected cases had? all started after the first year of life, and many survived into early and late childhood.

Dubowitz in 1964 described a further 12 cases of spinal muscular atrophy which had started before $₹$ the age of 18 months and appeared to have an 의 autosomal recessive inheritance. Most of the $D$ children presented had already reached late child-o hood, and again there seemed to be a great variation $\underset{\sim}{\sim}$ in severity. The disease seemed to progress rapidly o at first and thereafter to decline in severity so as to $N$ become almost stationary, leaving the patients with 
varying degrees of disability from residual weakness and contractures. There was neither intellectual deterioration nor upper motor neurone involvement. The diagnosis in nearly all the cases was confirmed electromyographically and histologically from muscle biopsy specimens. In one case the levels of the serum enzymes creatine phosphokinase and S.G.O.T. were slightly raised. In those cases that were familial, there was such variation in the severity of the disease that both Werdnig-Hoffmann and KugelbergWelander types of atrophy seemed to occur within the confines of a single family.

The most recent significant paper by Tsukagoshi, Nakanishi, Kondo, and Tsubaki (1965) describes five cases of a slowly progressive, hereditary proximal muscular atrophy, with symptoms beginning usually in the third or fourth decade. Clinically it closely resembled Kugelberg and Welander's condition except that in three of the cases there was bulbar palsy. Electromyographically there was evidence of a disorder of the spinal neurone. Muscle biopsy showed changes implying anterior horn cell damage, but also certain architectural abnormalities in some muscle fibres, such as central nuclei and isolated fibre necrosis, which suggested a myopathic element. These last changes could probably be correlated with the grossly elevated creatine phosphokinase levels which were found to occur in four of the cases.

\section{DISCUSSION}

The first two cases in this paper are very similar to those of Kugelberg and Welander, but are not obviously familial. However, an entirely accurate family history cannot be relied upon and in view of the limited sibships there could still be an underlying inherited basis. Clinically from the age of onset, distribution of weakness, and the rate of evolution it seems indistinguishable from a limbgirdle type of muscular dystrophy, but electromyographically and histologically differs completely. There is still the paradox that, although neurogenic in origin, these two cases have both shown abnormalities in serum enzymes which are normally associated with myopathic conditions rather than neurogenic atrophies. In a survey of enzyme values in a collection of mixed cases of neurogenic atrophy and muscular dystrophy patients, Okinaka, Kumagai, Ebashi, Sugita, Momoi, Toyokura, and Fujie (1961) showed that a rise in creatine phosphokinase was limited to patients with muscular dystrophy, their relatives, or occasionally patients with polymyositis or Charcot-Marie-Tooth disease. 4

Case 3 differs in that for many years it has simulated not muscular dystrophy but motor neurone disease. At first sight this patient appears to have the Aran-Duchenne type of motor neurone disease, in which muscular atrophy is the main feature, but this hardly seems a tenable diagnosis in a patient whose disease has progressed only mildly in over two score years and who still has no evidence of upper motor neurone damage. This case is in nearly all respects identical to the cases described by Tsukagoshi et al. (1965), even to the unusual muscle biopsy appearance which seemed to combine the features of neurogenic atrophy with some evidence of a myopathic process. The level of serum creatine phosphokinase was raised, although not to the same extent as in the cases of Tsukagoshi et al. (1965). The absence of a positive family history does not necessarily rule out a hereditary basis in view of the limited sibship and incomplete family data.

It is difficult to be certain of the precise relationship between these various forms of spinal muscular atrophy. Certainly, when one considers the WerdnigHoffmann and Kugelberg-Welander types of atrophy and the many documented cases ranging between them, even within the confines of a single family, it seems possible that one is dealing basically with a single condition which may combine variable ages of onset and rates of progress. The group of cases which start at a later age than the infantile and juvenile groups, such as case 3 above and the cases of Tsukagoshi et al. (1965), are in many ways similar and may be related, although there seems to be less overlap between these cases and those occurring at an earlier age. More extensive series are required to see whether infantile and juvenile forms may occur in the same family setting as the later adult cases.

Finally, it is worth briefly considering whether there could be any relationship between the various forms of chronic spinal muscular atrophy, hereditary or otherwise, and motor neurone disease. Motor neurone disease can occasionally occur hereditarily and this topic has been discussed in detail by Kurland and Mulder (1955). However, familial motor neurone disease usually presents as a rapidly progressive amyotrophic lateral sclerosis, with dominant inheritance, rather than as pure progressive muscular atrophy. Also in those cases of motor neurone disease in which muscular atrophy predominates, the wasting tends initially to be distal rather than proximal as is seen in the chronic spinal muscular atrophies. There is thus no real evidence to suggest any close relationship between motor neurone disease and the chronic spinal atrophies seen in adult life, and indeed, in view of the marked difference in course and prognosis, it is important to try and distinguish between them. 


\section{SUMMARY}

Three cases were presented of chronic muscular atrophy occurring in adult males with the histological and electromyographic characteristics of atrophy due to damage to the spinal motor neurone.

Two of the cases were in most respects similar to those described by Kugelberg and Welander, but differed in the absence of a positive family history.

The third case occurring in an older man was similar in most respects to the cases recently described by Tsukagoshi et al. (1965), but again differed in the absence of a positive family history.

I wish to thank Dr. R. E. Kelly for help and permission to publish the reports of cases under his care, Dr. R. W. Ross-Russell for advice and guidance, Dr. P. Bauwens and Dr. D. A. H. Yates for electromyographic studies, and Dr. J. R. Tighe for the photomicrographs.

\section{REFERENCES}

Brandt, S. (1950). Course and symptoms of progressive infantile muscular atrophy. Arch. Neurol. Psychiat. (Chic.), 63, 218-228.

Byers, R. K., and Banker, B. Q. (1961). Infantile muscular atrophy. Arch. Neurol. (Chic.), 5, 140-164.
Dubowitz, V. (1964). Infantile muscular atrophy, a prospective study $Z$ with particular reference to a slowly progressive variety. Brain, 87, 707-718.

Hoffmann, J. (1893). Ueber chronische spinale Muskelatrophie im $\overline{\widehat{C}}$ Kindesalter, auf familiärer Basis. Dtsch. Z. Nervenheilk., 3, 427-470.

(1897). Weiterer Beitrag zur Lehre von der hereditären progressiven spinalen Muskelatrophie im Kindesalter nebst Bemerkungen über den fortschreitenden Muskelschwund im Allgemeinen. Ibid., 10, 292-320.

Kugelberg, E., and Welander, L. (1956). Heredofamilial juvenile $\frac{\vartheta}{2}$ muscular atrophy simulating muscular dystrophy. Arch. Neurol. (Chic.), 75, 500-509.

Kurland, L. T., and Mulder, D. W. (1955). Epidemiologic investigations of amyotrophic lateral sclerosis. 2. Familial aggregations $\overrightarrow{\hat{T}}$ indicative of dominant inheritance. Neurology (Minneap.), 5, 182-196, and 249-268.

Okinaka, S., Kumagai, H., Ebashi, S., Sugita, H., Momoi, H., ত Toyokura, Y., and Fujie, Y. (1961). Serum creatine phospho- $\overline{\bar{C}}$ kinase activity in progressive muscular dystrophy and neuro- $\vec{T}$ muscular diseases. Arch. Neurol. (Chic.), 4, 520-525.

Tsukagoshi, H., Nakanishi, T., Kondo, K., and Tsubaki, T. (1965). Hereditary proximal neurogenic muscular atrophy in adult. Ibid., 12, 597-603.

Werdnig, G. (1891). Zwei frühinfantile hereditäre Fälle von pro- $\vec{\odot}$ gressiver Muskelatrophie unter dem Bilde der Dystrophie, aber auf neurotischer Grundlage. Arch. Psychiat. Nerven- $\vec{\omega}$ kr., 22, 437-480.

- (1894). Die frühinfantile progressive spinale Amyotrophie. Ibid., 26, 706-744.

Wohlfart, G., Fex, J., and Eliasson, S. (1955). Hereditary proximal spinal muscular atrophy-a clinical entity simulating progres- iv sive muscular dystrophy. Acta psychiat. scand., 30, 395-406. 